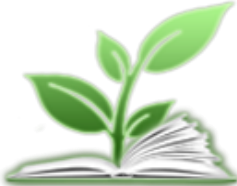

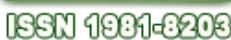

Revista Verde de Agroecologia e Desenvolvimento Sustentável

http://www.gvaa.com.br/revista/index.php/RVADS

ARTIGO CIENTÍFICO

DOI: http://dx.doi.org/10.18378/rvads.v10i5.3622

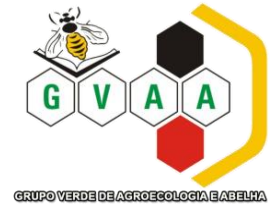

\title{
Crescimento de genótipos de feijão-caupi irrigados com água salina
}

\section{Growth bean-cowpea genotypes irrigated with saline water}

\author{
Kyonelly Queila Duarte Brito ${ }^{1}$, Ronaldo do Nascimento ${ }^{2}$, Ivis Andrei Campos e Silva ${ }^{3}$, Joyce Edja Aguiar dos Santos ${ }^{4}$,Felipe \\ Guedes de Souza. ${ }^{5}$
}

\begin{abstract}
Resumo: O feijão-caupi tem grande importância socioeconômica, pois é um componente da dieta alimentar, especialmente pelo seu valor nutritivo e fonte de renda para agricultura familiar. Entretanto é uma cultura sensível a salinidade da água de irrigação e solo, o que impossibilita o cultivo em áreas afetadas por sais. Neste sentido, objetivou-se com o trabalho avaliar o crescimento de genótipos de feijão-caupi irrigados com água salina, a fim de fornecer subsídios ao cultivo em regiões afetadas por sais. A pesquisa foi desenvolvida em casa de vegetação da Universidade Federal de Campina Grande. Utilizou-se o delineamento experimental inteiramente casualizado, em esquema fatorial 2 x 5, sendo os tratamentos compostos de dois níveis de condutividade elétrica da água (A1 - água de abastecimento com $0,8 \mathrm{dSm}^{-1}$ e A2 - solução salina $4,8 \mathrm{dSm}^{-1}$ ) e cinco genótipos de feijão-caupi (G1 - MNC04-762F-9, G2 - MNC04-762F-3, G3 - MNC04-762F-21, G4 - MNC04-769F-62 e G5 MNC04-765F-153) com 4 repetições, resultante em 10 tratamentos. Aplicação dos tratamentos com água salina teve inicio aos 12 dias após o semeio (DAS). As variáveis analisadas foram, altura de plantas (ALT), número de folhas (NF), e diâmetro do caule (DC), nas épocas de avaliação correspondente aos 27, 42, 57 e 72 dias após a semeadura (DAS) e massa seca das folhas (MSF), massa seca do caule (MSC), massa seca da raiz (MSR) e massa seca da parte aérea (MSPA). A salinidade da água de irrigação reduziu todas as variáveis de crescimento e fitomassa avaliadas.
\end{abstract}

Palavras-chaves: Vigna unguicula L. Walp, salinidade, tolerância.

\begin{abstract}
The cowpea has great socio-economic importance, as it is a component of food people diet, especially in developing countries. Sensitive to salinity, which makes difficult to cultivate in areas affected by salt. The objective of the study was to evaluate the growth of cowpea genotypes irrigated with saline water in order to provide subsidies to farming in areas affected by salt. The treatments consisted of the combination of two factors: Irrigation Water Salinity (A1 - water supply with $0,8 \mathrm{dSm}-1$ and A2 - saline solution $4.8 \mathrm{dSm}-1$ ) and cowpea genotypes (G1 - MNC04-762F -9, G2 - MNC04-762F-3 G3 - MNC04-762F21 G4 - G5 and MNC04-769F-62 - MNC04-765F-153). Combined factors, a completely randomized design, resulted in 10 treatments, with four repetitions. The irrigation with saline water given to the 12 DAS. The variables analyzed were plant height (PH), leaves number (LN), and stem diameter (SD), the evaluation of times corresponding to $27,42,57$ and 72 days after sowing (DAS) and dry matter leaves (DML), dry mass of the stem (DMS) and root dry mass (RDM). They salinity of irrigation water reduced all growth variables and evaluated biomass.
\end{abstract}

Key words: Vigna unguicula L. Walp, salinity, tolerance.

\footnotetext{
*Autor para correspondência

Recebido para publicação em 31/08/2015; aprovado em 20/11/2015

${ }^{1}$ Mestrando UAEAg/CTRN/UFCG. Campina Grande - PB. E-mail: queiladuarte@ hotmail.com

2 Professor Doutor UAEAg/CTRN/UFCG. Campina Grande - PB E-mail: ronaldo@ deag.ufcg.edu.br

${ }^{3}$ Graduando, UAEAg/CTRN/UFCG. Campina Grande - PB. E-mail: ivisandrei@gmail.com

${ }^{4}$ Mestrando, UAEAg/CTRN/UFCG. Campina Grande - PB. E-mail: joycedja@ hotmail.com

${ }^{5}$ Mestrando, UAEAg/CTRN/UFCG. Campina Grande - PB. E-mail: felipeguedesjm_16@hotmail.com
} 


\section{INTRODUÇÃO}

O feijão-caupi é uma dicotyledonea, pertencente à ordem Fabales, família Fabaceae, subfamília Faboideae, da espécie Vigna unguiculata (L.). Grão nativo da África e bastante cultivado nas regiões tropicais dos continentes africano, asiático e americano (SOARES et al., 2006).

Segundo Wander (2007), nos últimos 20 anos a cultura do feijão (feijão-comum + feijão-caupi) passou por intensas modificações, destacando-se o aumento da produtividade, principalmente na terceira safra, e a concentração da produção em regiões mais favorecidas. Mostra ainda que em 2005 a produção de feijão-caupi correspondeu a aproximadamente $20 \%$ da produção total de feijão do País.

O grão tem grande importância socioeconômica, pois é um componente da dieta alimentar de povos, especialmente em países subdesenvolvidos. Rico em proteína, minerais e fibras (FROTA et al., 2008) se constitui na principal fonte protéica vegetal para famílias de baixa renda do Nordeste brasileiro. No entanto, a produtividade nessa região ainda é baixa, devido, ao déficit hídrico que ocorre durante mais de seis meses no ano, aliado ás temperaturas elevadas, necessitando-se de irrigação (Azevedo, 2003), além desses fatores existe ainda problemas de salinidade em função dos elevados teores de sais de parte de suas fontes de água, associados ao manejo inadequado da irrigação e de drenagem. Isso tem ocasionado redução no crescimento e na produtividade das culturas, além do abandono de lotes de terra nos perímetros de irrigação da região (DANTAS et al., 2002).

A salinidade pode afetar culturas de maneiras diferentes, ou seja, algumas conseguem um desenvolvimento e produção satisfatória em níveis de salinidade mais elevadas outras já sofrem bastante ao decorrer de seu desenvolvimento. De acordo com Cavalcante et al.(2010) o estresse salino provoca a redução do desenvolvimento vegetal em função dos desequilíbrios nutricionais provocados pelo excesso de sais na absorção e transporte de nutrientes. Farias et al. (2009) afirmam que a salinidade, reduz a atividade dos íons em solução e altera os processos de absorção, transporte, assimilação e distribuição de nutrientes na planta. Diante disto objetivou-se com este trabalho avaliar o crescimento de genótipos de feijão-caupi irrigados com água salina, a fim de fornecer subsídios ao cultivo desta leguminosa em regiões afetadas por sais.

\section{MATERIAL E MÉTODOS}

A pesquisa foi desenvolvida em condições de ambiente protegido (casa de vegetação) da Universidade Federal de Campina Grande, nas instalações da Unidade Acadêmica de Engenharia Agrícola/UFCG, Centro de Tecnologia e Recursos Naturais, em Campina Grande, PB. A UFCG está localizada na zona centro oriental do Estado da Paraíba, no Planalto da Borborema. Conforme o Instituto Nacional de Metodologia (INMET), o município apresenta precipitação total anual de $802,7 \mathrm{~mm}$, temperatura máxima de $27,5^{\circ} \mathrm{C}$, mínima de $19,2^{\circ} \mathrm{C}$ e umidade relativa do ar de $83 \%$.

Utilizou-se o delineamento experimental inteiramente casualizado, em esquema fatorial 2 x 5, sendo os tratamentos compostos de dois níveis de condutividade elétrica da água (A1 - água de abastecimento com $0,8 \mathrm{dSm}^{-1}$ e A2 - solução salina $4,8 \mathrm{dSm}^{-1}$ ) e cinco genótipos de feijão-caupi (G1 MNC04-762F-9, G2 - MNC04-762F-3, G3 - MNC04-762F21, G4 - MNC04-769F-62 e G5 - MNC04-765F-153) com 4 repetições, resultante em 10 tratamentos.

As plantas foram conduzidas em vasos de polietileno, com $20 \mathrm{Kg}$ de solo esterilizado, e adubado, de acordo com Novais et al.(1991), para ambiente controlado em vasos. Os vasos foram colocados em capacidade de campo, e germinouse 3 sementes por vaso, a uma profundidade de $2 \mathrm{~cm}, 10$ dias após a semeadura realizou-se o primeiro desbaste, sendo deixada as duas plantas mais vigorosas, aos 12 dias após a semeadura (DAS) realizou-se o segundo desbastes.

A irrigação com água salina teve início aos 12 DAS. As irrigações foram diariamente e de forma manual, com base no consumo de água das plantas na irrigação anterior, dividindose o volume estimado pelo fator 0,8 , restabelecendo-se, assim, a umidade do solo à capacidade de campo e se obtendo uma fração de lixiviação (FL) de aproximadamente $20 \%$ (Eq. 1): [VI=(VA-VD)/1-FL], em que, VI, VA, VD são volume de água a ser aplicado na irrigação, volume de água aplicado e drenado na irrigação anterior, respectivamente $(\mathrm{ml})$

A solução de água salina para irrigação foi preparada a partir do sal $\mathrm{NaCl}$, feitas as avaliações de condutividade elétrica (CE) das água de abastecimento e salina, até alcançarem o valor desejado.

Os dados foram avaliados para se analisar o crescimento do feijão-caupi, em função dos tratamentos testados, por meio das observações não destrutivas.

Foram avaliados a cada 15 dias, a parti do inicio da irrigação com água salina, o número de folhas (NF), contando-se aquelas completamente expandidas ou com o valor mínimo de $3 \mathrm{~cm}$; a altura das plantas (ALT), medindose desde a base do caule até a ultima inserção foliar; e o diâmetro do caule (DC) a uma altura de dois centímetros do solo, com auxilio de um paquímetro digital.

No final do experimento aos 75 DAS, foram determinadas as variáveis de massa seca, radicular (MSR), folhas (MSF), caule (MSC) e parte aérea (MSPA), para MSPA obtida a partir do somatório da MSF e MSC. Para a determinação das massas secas, as plantas foram coletadas e levadas para o laboratório de irrigação e salinidade do Departamento de Engenharia Agrícola da UFCG, onde foram selecionados caule, folhas e raiz; sendo acondicionadas em sacos de papel e postos para secar em estufa de circulação forçada de ar, mantida na temperatura de $60^{\circ} \mathrm{C}$, até atingir peso constante, quando então foi determinada a MSF, MSC, MSR e MSPA.

Os dados obtidos foram submetidos à análise de variância pelo teste ' $F$ ' e nos casos de significância com o teste de Tukey a $5 \%$ de probabilidade para a comparação das médias. Utilizando o programa Sisvar 5.3.

\section{RESULTADOS E DISCUSSÃO}

Conforme o resumo de analise de variância (Tabela 1) para as variáveis de altura de plantas (ALT), número de folhas (NF), e diâmetro do caule (DC), nas épocas de avaliação correspondente aos 27, 42, 57 e 72 dias após a semeadura (DAS). Nota-se efeito significativo $(\mathrm{p}<0,01$ e $\mathrm{p}<0,05)$ entre os genótipos $(\mathrm{GEN})$, para NF, para ALT observa-se efeito significativo do 'tratamento' em todas as 
épocas avaliadas, e para NF a partir dos 42 DAS. Verifica-se interação genótipo e salinidade aos 42 e 72 DAS para DC.

Souza et al. (2007), estudando a salinidade no desenvolvimento do feijão-caupi, também encontraram resposta significativa nas mesmas as características avaliadas.

Tabela 1. Resumo da análise de variância para altura de plantas (ALT) $(\mathrm{cm})$, número de folhas $(\mathrm{NF})$ e diâmetro do caule (DC) (mm) em genótipos de feijão-caupi sob irrigação com água salina. Campina Grande, 2014

\begin{tabular}{|c|c|c|c|c|c|}
\hline \multirow[b]{2}{*}{ DAE } & \multirow[b]{2}{*}{ FV } & \multirow[b]{2}{*}{$\mathrm{G}$} & \multicolumn{3}{|c|}{ Quadrados Médios } \\
\hline & & & ALT & $\mathrm{NF}$ & $\mathrm{DC}$ \\
\hline \multirow{5}{*}{27} & Tratamento & 1 & $32,40^{* *}$ & $0,22^{\mathrm{ns}}$ & $5,62^{\mathrm{ns}}$ \\
\hline & Genótipo $(\mathrm{G})$ & 4 & $7,12^{\mathrm{ns}}$ & $1,47^{* *}$ & $1,22^{\mathrm{ns}}$ \\
\hline & $\mathrm{T} \times \mathrm{G}$ & 4 & $4,40^{\mathrm{ns}}$ & $0,22^{\mathrm{ns}}$ & $0,62^{\mathrm{ns}}$ \\
\hline & Erro & 27 & 5,39 & 0,36 & 2,34 \\
\hline & $\mathrm{CV}(\%)$ & & 12,22 & 14,51 & 22,43 \\
\hline \multirow{5}{*}{42} & Tratamento & 1 & $688,90^{*}$ & $160,00^{*}$ & $57,60^{*}$ \\
\hline & Genótipo (G) & 4 & $41,37^{\mathrm{ns}}$ & $20,08^{* *}$ & $14,40^{* *}$ \\
\hline & $\mathrm{T} \times \mathrm{G}$ & 4 & $18,77^{\mathrm{ns}}$ & 11,68 & $13,47^{* *}$ \\
\hline & Erro & 27 & 18,79 & 5,88 & 4,91 \\
\hline & $\mathrm{CV}(\%)$ & & 13,44 & 27,41 & 19,03 \\
\hline \multirow{5}{*}{57} & Tratamento & 1 & $448,90^{*}$ & $672,40^{*}$ & $72,90^{*}$ \\
\hline & Genótipo $(\mathrm{G})$ & 4 & $39,85^{* *}$ & $40,97^{*}$ & $1,78^{\mathrm{ns}}$ \\
\hline & $\mathrm{T} \times \mathrm{G}$ & 4 & $4,40^{\mathrm{ns}}$ & $38,40^{*}$ & $1,96^{\mathrm{ns}}$ \\
\hline & Erro & 27 & 11,97 & 5,94 & 2,67 \\
\hline & $\mathrm{CV}(\%)$ & & 10,19 & 19,83 & 14,60 \\
\hline \multirow{5}{*}{72} & Tratamento & 1 & $592,90^{*}$ & & $65,02^{*}$ \\
\hline & Genótipo (G) & 4 & $54,41^{* *}$ & & $3,53^{\mathrm{ns}}$ \\
\hline & $S \times G$ & 4 & $11,46^{\mathrm{ns}}$ & & $1,46^{*}$ \\
\hline & Erro & 27 & 14,10 & & 2,48 \\
\hline & $\mathrm{CV}(\%)$ & & 10,45 & & 13,62 \\
\hline
\end{tabular}

$\mathrm{ns}, * *$, * respectivamente não significativo a $\mathrm{p}<0,01$ e $\mathrm{p}<0,05$.

Os genótipos estudados tiveram respostas diferentes quanto à altura de plantas. Na Figura 1, pode-se observar o comportamento entre esses genótipos, aos 57 e 72 DAS, onde ocorreu efeito significativo $(\mathrm{p}<0,01)$.

O teste de médias para a altura de plantas aos 57 DAS ( figura 1), em que o G5 e G1 obtiveram as maiores médias em relação aos demais genótipos. O genótipo G2 possui a menor média de altura de plantas em relação aos demais genótipos, com diferença de $23,88 \%$ para o G5 que possui maior média.

No entanto, em relação ao tratamento, o G2 obteve menor diferença, sendo o tratamento com água salina $15,51 \%$ menor do que com água de abastecimento. Já o G5 que obteve maior diferença entre os tratamentos, sendo o tratamento com água 2 (água salina) menor $25,75 \%$ do que a água1( água de abastecimento).

A diferença de altura entre o genótipo que obteve menor média e o de maior média foi de $6 \mathrm{~cm}$ e $7 \mathrm{~cm}$, aos 57 e 72 DAS, respectivamente.
Figura1. Quadro do teste de médias para a altura de plantas de genótipos de feijão-caupi irrigados com águas salinizadas aos 57(A) e 72(B) DAS. Campina Grande, PB, 2014.

A)

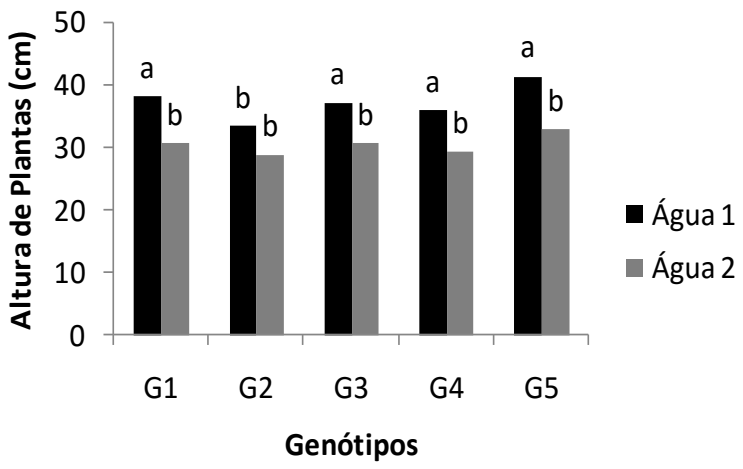

B)

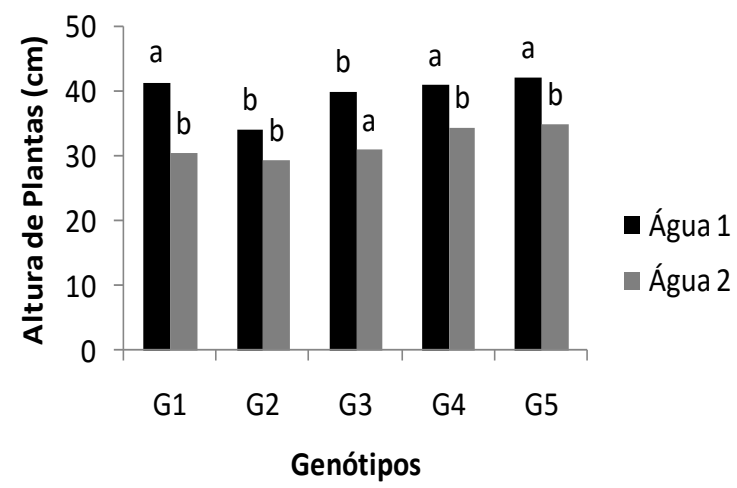

Ainda aos 27 e 42 DAS, pode-se observar (Figura 2) para NF em função dos cinco genótipos de feijão-caupi, os quais apresentam diferentes comportamentos em relação ao número de folhas com efeito da irrigação com água salina.

Na Figura 2A observar-se o comportamento entre os genótipos, em relação ao número de folhas, sendo a melhor média 4,75 obtida com o genótipo G1. Já os genótipos G4 e G5, foram os que obtiveram menos NF $(3,75)$. Aos 42 DAS (Figura 2B) a maior diferença entre os tratamentos foi apresentada pelo genótipo G1, em que as plantas irrigadas com água de abastecimento apresentaram 96,55\% a mais de número de folhas do que as plantas irrigadas com a condutividade de $4,8 \mathrm{dS} \mathrm{\textrm {m } ^ { - 1 }}$. O genótipo G2 possui menor diferença entre os tratamentos sendo equivalente a $20,59 \%$ de diferença do número de folhas, tendo melhor resposta a utilização da irrigação com água salina.

Observa-se uma variação no número de folhas entre os genótipos, podendo ser atribuídos esse fato as diferenças genéticas dos grãos de feijão-caupi. Dantas et al. (2002), trabalhando com 50 genótipos de caupi sob condições de salinidade, constataram que todos os genótipos apresentaram reduções significativas na produção de matéria seca das folhas em função do aumento da salinidade do solo. 
Figura 2. Quadro do teste de médias para o número de folhas de genótipos de feijão-caupi irrigados com águas salinizadas aos 27 e 42 DAS. Campina Grande, PB, 2014.

A)

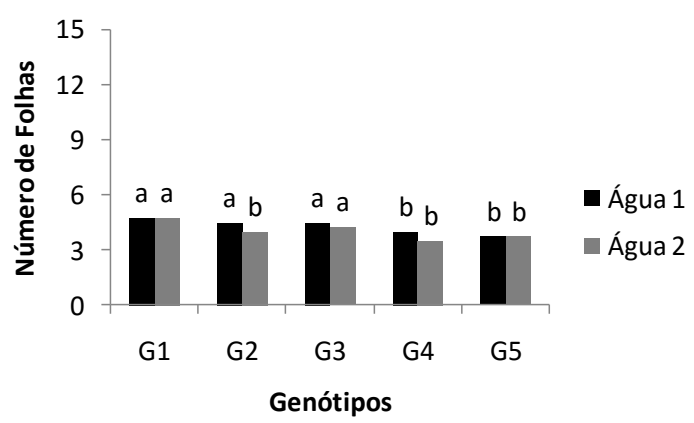

B)

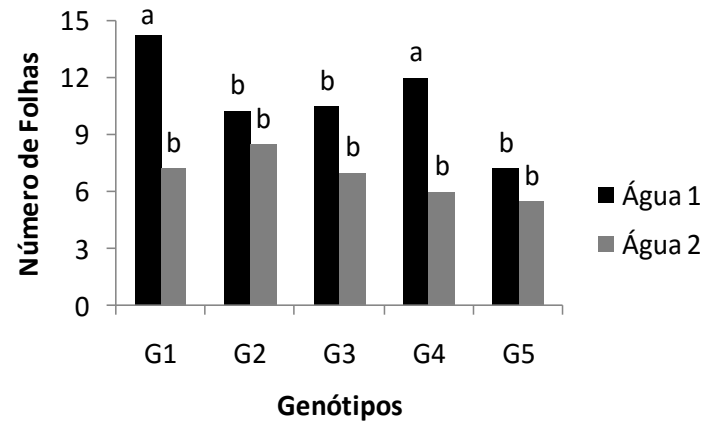

Aos 57 DAS ocorreu interação entre o tratamento utilizado e genótipos (Figura 3). Para todos os genótipos estudados, a salinidade influenciou negativamente o número de folhas. Verifica-se que os genótipos estudados apresentaram comportamentos diferenciados em relação aos tratamentos, em destaque o G3, que mesmo com o tratamento com água de abastecimento (Água 1), obteve média menor que outros genótipos com irrigação com água salinizada.

Os demais genótipos, G1, G2, G4 E G5, apresentam médias maiores com o tratamento com a Água1. Este comportamento demonstra que o efeito da salinidade sobre o crescimento das plantas é variável em função do material genético utilizado, estando assim de acordo com Parida e Das (2005). Trabalhos desenvolvidos com outras culturas também puderam evidenciar esse comportamento, como observado com feijãocaupi (SANTOS et al., 2009), o que evidencia a importância da seleção de genótipos para cultivo em condições ambientais em que seja inevitável o uso de água salina para irrigação.

Figura 3. Teste de médias para interação de número de folhas e tratamentos aos 57 DAS. Campina Grande, PB, 2014.

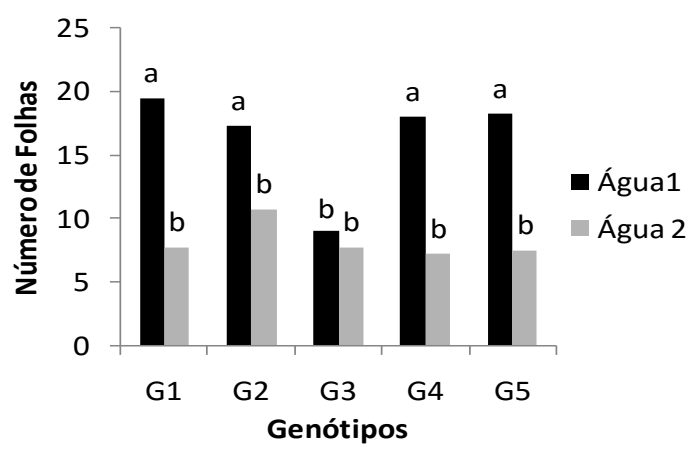

$\mathrm{Na}$ Figura 4, observa-se o efeito significativo $(\mathrm{p}<0,05)$ para a interação de genótipo e tratamento em relação ao diâmetro do caule, nesta variável os genótipos comportaram-se de maneira diferente dentro dos níveis de sais. Sendo destaque o G1 que obteve maior média em relação aos demais genótipos e o G2 com menores médias em ambos os tratamentos.

O genótipo $\mathrm{G} 4$, apresentou menor diferença entre os tratamento, com diferença de $2,1 \%$, já o G5 obteve a maior diferença de $67,5 \%$ entre os tratamentos.

Segundo Morales et al. (2001), nem todas as partes da planta são igualmente afetadas pela salinidade, bem como, a adaptação ao estresse salino varia entre espécies e em um mesmo genótipo pode variar entre estádios fenológicos.

Figura 4. Teste de médias para interação de diâmetro do caule e tratamentos aos 42DAS. Campina Grande, PB, 2014.

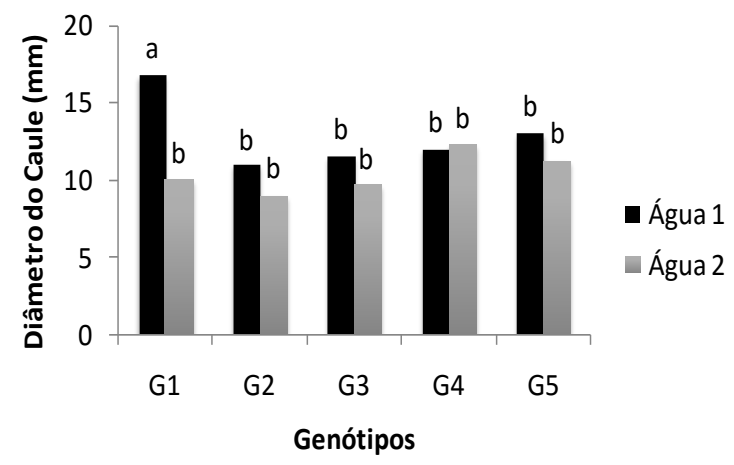

Conforme o resumo da analise de variância (Tabela 2), observa-se que a massa seca das folhas (MSF), caule (MSC), raízes (MSR) e da parte aérea (MSPA), apresentam diferenças significativas para o tratamento, em todas as variáveis avaliadas. Entretanto não houve efeito significativo entre os genótipos estudados. O tratamento, utilizando água salina na irrigação, influencia a $5 \%$ todos os parâmetros avaliados.

Tabela 2. Resumo da análise de variância para massa seca das folhas (MSF), massa seca do caule (MSC), massa seca da raiz(MSR) e massa seca da parte aérea (MSPA) em genótipos de feijão-caupi sob irrigação com água salina. Campina Grande, 2014.

\begin{tabular}{cccccc}
\hline & \multicolumn{4}{c}{ Quadrados Médios } \\
\cline { 2 - 6 } FV & GL & MSF & MSC & MSR & MSPA \\
\hline Tratamento(T) & 1 & $140,62^{*}$ & $525,62^{*}$ & 180,62 & $1144,90^{*}$ \\
Genótipo(G) & 4 & $3,56^{\mathrm{ns}}$ & $3,75^{\mathrm{ns}}$ & $5,162^{\mathrm{ns}}$ & $4,96^{\mathrm{ns}}$ \\
T X G & 4 & $3,06^{\mathrm{ns}}$ & $2,00^{\mathrm{ns}}$ & $1,43^{\mathrm{ns}}$ & $5,96^{\mathrm{ns}}$ \\
Erro & 27 & 3,17 & 4,04 & 2,83 & 9,88 \\
CV $(\%)$ & & 16,78 & 25,55 & 30 & 17,08
\end{tabular}

$\mathrm{ns}, * *, *$ respectivamente não significativo a $\mathrm{p}<0,01$ e $\mathrm{p}<0,05$.

A Figura 5 apresenta o teste de médias, para MSF, MSC e MSR, onde ocorreu efeito significativo a 5\% para o fator de tratamento. Na Figura 5A, observa-se que a maior média para a massa seca foliar é a do genótipo G1 $(14,25 \mathrm{~g})$, seguido do G2 (12,75g), diferindo das maiores médias encontramos o G5 (11,25g), com menor média. Com avaliação levando em consideração os tratamentos o genótipo que apresentou maios diferença foi o G1 $(63,14 \%)$. 
Para a variável de massa seca do caule (Figura 5B), as maiores médias encontradas foram a dos genótipos G1 e G2 (12,75 e 12,50g respectivamente), para o fator de tratamento o $\mathrm{G} 2$, continuou obtendo maior média. A massa seca das raízes (Figura 5C), o genótipo G1 obteve maior média $(7,25 \mathrm{~g})$ no tratamento correspondente a água de abastecimento, diferindo do genótipo G5 que obteve menor média $(5,50 \mathrm{~g})$. Para o tratamento com a irrigação com água salina o genótipo que obteve melhor resposta foi o G1 com o peso médio de $4,25 \mathrm{~g}$ e o G3, G4 e G5 com menores médias de $1,75 \mathrm{~g}$ cada um.

Importante destacar que o uso de águas salinas na irrigação do feijão-caupi provoca acúmulo de sais no solo e reduz o crescimento vegetativo e a produção de grãos, sugerindo que a utilização de água salina na irrigação depende de algumas estratégias de manejo que garantam a sustentabilidade socioeconômica e ambiental dos sistemas agrícolas (BEZERRA et al., 2010).

Figura 5 . Teste de médias para massa seca das folhas (MSF), massa seca do caule (MSC) e massa seca da raiz(MSR). Campina Grande, PB, 2014.

A)

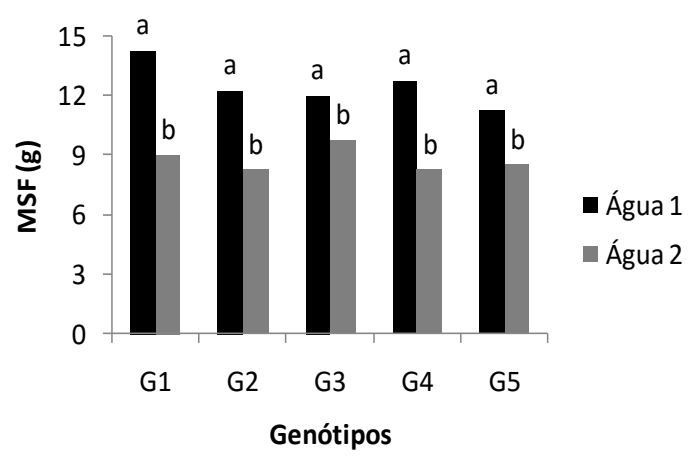

B)

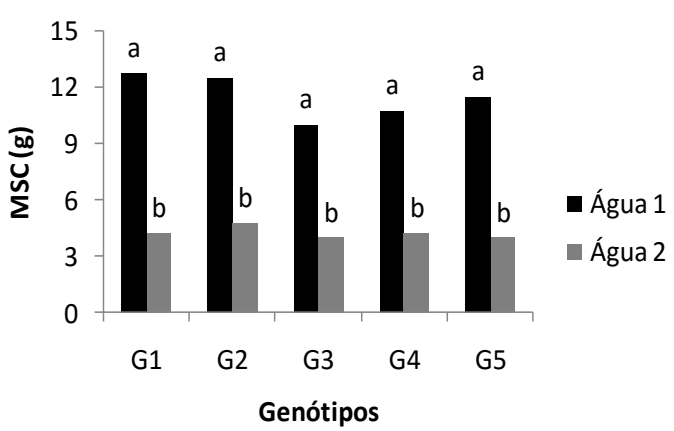

C)

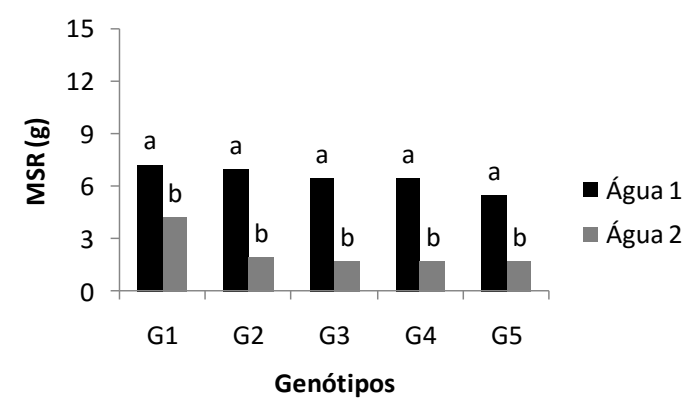

\section{CONCLUSÕES}

A salinidade da água de irrigação reduziu todas as variáveis de crescimento e massa seca avaliadas.

Com base nas variáveis de crescimento, foram identificados como genótipos mais tolerantes a salinidade os G2 e G3, e os mais sensíveis a salinidade da água de irrigação, são os G1, G4 e G5. Para as variáveis de massa seca todos os genótipos apresentaram sensibilidade a água de irrigação com alta concentração de sais.

\section{REFERÊNCIAS BIBLIOGRÁFICAS}

BEZERRA, A. K. P.; LACERDA, C. F.; HERNANDEZ, F. F. F.; SILVA, F. B.; GHEYI, H. R. Rotação cultural feijão caupi/milho utilizando-se águas de salinidades diferentes. Ciência Rural, v. 40, n. 05, p. 1075-1082, 2010 .

DANTAS, J. P.; MARINHO, F. J. L.; AMORIM, M. S. N.; ANDRADE, S. I. O.; SALES, A. L. Avaliação de genótipos de caupi sob salinidade. Revista Brasileira de Engenharia Agrícola e Ambiental, Campina Grande, v.6, n.3, p.425-430, 2002.

FREIRE, M. B. G. S. \& FREIRE, F. J. Fertilidade do solo e seu manejo em solos afetados por sais. In: NOVAIS, R. F.; et al. (ed.). Fertilidade do solo. Viçosa: Sociedade Brasileira de Ciência do Solo. p. 929-954, 2007.

FROTA, K. M. G.; SOARES, R. A. M.; ARÊAS, J. A. G. Composição química do feijão caupi (Vigna unguiculata L. Walp), cultivar BRS milênio. Ciência e Tecnologia de Alimentos, Campinas, v. 28, n. 2, p. 470-476, 2008.

MORALES, M.A.; OLMOS, E.; TORRECILLAS, A.; ALARCON, J.J. Differences in water relations, leaf ionaccumulation and excretion rates between cultivated and wild species of Limonium sp. grown in conditions of saline stress. Flora, Jena, v.196, n.5, p.345-352, 2001.

NOVAIS, R .J.; NEVES, J. C. L.; BARROS, N. F. Ensaios em ambiente controlado. In: OLIVEIRA, A. J. de.; GARRIDO, W. E.; ARAÚJO, J. D.; LOURENÇO, L. Métodos de pesquisa em fertilidade do solo. Brasília: Embrapa, p.189-254, 1991.

PARIDA, A. K.; DAS, A. B. Salt tolerance and salinity effects on plants: A review. Ecotoxicology and Environmental Safety, v.60, p.324-349, 2005.

PEREIRA, C. P. Um, dois, feijão com arroz. Revista Saúde, Natal, v. 294, p. 14-17, 2008.

SANTANA, M.J.; CARVALHO, J.A.; ANDRADE, M.J.B.; SILVA, E.L. Desenvolvimento do feijoeiro (Phaseolus vulgaris L. cv. ESAL 686) sob irrigação com água salina. Irriga, Botucatu, v.8, n.1, p.29-36, 2003.

SANTOS, P.R. et al. Germinação, vigor e crescimento de cultivares de feijoeiro em soluções salinas. Revista Brasileira de Engenharia Agrícola e Ambiental, v.13, supl, p.882-889, 2009. 
SOARES, A.L.; PEREIRA, JPAR; FERREIRA, PAAF; VALE, HMM; LIMA, AS;. Eficiência agronômica de rizóbios selecionados e diversidade de populações nativas nodulíferas em Perdões (MG). I - caupi. Revista Brasileira de Ciência do Solo, 30:795-802, 2006.

SOUSA, R.A.; LACERDA, C.F.; AMARO FILHO, J.; HERNANDEZ, F.F.F. Crescimento e nutrição mineral do feijão-de-corda em função da salinidade e da composição iônica da água de irrigação. Revista Brasileira de Ciências Agrárias. Recife, v.2, n.1, p.7582, 2007

WANDER, A. E. Produção e consumo de feijão no Brasil, 1975-2005. Informações Econômicas, São Paulo, v. 37, n. 2, p.7-21, fev. 2007. 